\title{
High Performance Three-Phase Boost-Type Voltage Regulator
}

\author{
T.S. Radwan, MIEEE \\ Electrical Engineering Department, \\ Faculty of Engineering, Menoufiya University, \\ Shebin El-Kom, EGYPT
}

\begin{abstract}
In this paper a new high performance three-phase boost-type voltage regulator is proposed. A control strategy, that provides regulated ac output voltage with low harmonic contents is suggested. The new boost regulator has nearly unity input power factor for a change in the load voltage up to $200 \%$ of the supply voltage. The four-quadrant nature of the proposed regulator enables it to accept reactive loads. Theoretical analysis and hardware implementation are developed. The results show the efficacy of the proposed regulator.
\end{abstract}

\section{Introduction}

Conventional ac regulations have been obtained either by using servo-controlled autotransformers or electrically controlled tap changing transformers [1]. Although, the servocontrolled auto-transformers gave better responses in term of output regulation and ripple contents, it is bulky and the conversion efficiency is not very high. Moreover, it contains moving parts and need regular maintenance. On the other hand, in electronic tap changing schemes, current regulation may be incorporated but they have the disadvantage of stepwise control and introduce spikes during tap changing period. Presently, switch mode regulators are becoming attractive due to absence of moving parts and ability of continuous control. Switch mode regulators controlled by pulse width modulation (PWM) are particularly attractive because of their simple control schemes. However, direct ac-ac voltage controllers in PWM mode of operation suffers from current chopping phenomena in the case of inductive loads. To avoid this, ac-ac voltage controllers are designed with a dc link (ac-dc-ac converters). In these schemes, the front-end converter introduces harmonics in the supply and gives poor power factor. Direct ac-ac conversion is also being implemented by switching regulators using high frequency electronic transformer interface and by quasi-resonant converters with zero current switching [2-6]. These schemes provide high efficiency but they are suitable for low power applications only. Also, these systems are suitable only for buck mode applications. A thyristor-controlled transformer booster has been suggested and examined [7], but such devices are of limited range and

\footnotetext{
Manuscript received from Dr. T.S RADWAN on : $8 / 2 / 2000$

Accepted on : 4/3/2000

Engineering Research Bulletin, Vol 23,No 2, 2000 Minufiya University, Faculty of Engineering, Shebien EI-Kom , Egypt, ISSN 1110-1180
} 
introduce distortion in the voltage waveform. Saturable reactor voltage regulator with improved current waveforms was obtained [8], but distortion was noticeable at low levels of output voltage. Different topologies and control techniques were proposed [9] to realize unity power factor at the ac source side, but large number of switches and sophisticated control techniques were required for ac-dc-ac conversion system.

PWM controlled direct ac/ac voltage regulators has been examined in $[10,11]$. Although high input power factor has been achieved, these types of regulators were used in buck mode only. A new three-phase boost-type voltage regulator was proposed in [12]. This regulator uses two independent hysteresis current controllers to obtain regulated output voltage.

In this paper, a new control strategy for high performance three-phase boost regulator is proposed. The principle of operation and control of the regulator are presented. General equations of the regulator covering different modes of operations are derived and used for transient and dynamic simulation. A 750VA laboratory prototype of the boost regulator has been built and tested. Simulation and experimental results are reported and discussed.

\section{Circuit Topology, Operation and Control}

\section{A. The circuit topology}

The configuration of the proposed three-phase boost-type ac voltage regulator is shown in Fig.1. In this configuration, only four ac switches, $S_{a a}, S_{a c}, S_{b b}$ and $S_{b c}$ are used and arranged as shown in the figure. The ac switches and the boost inductors, $\mathrm{L}_{\mathrm{Ba}}, \mathrm{L}_{\mathrm{Bb}}$, and $\mathrm{L}_{\mathrm{Bc}}$ are located between the ac source and the load. Moreover, three delta-connected ac capacitors, $\mathrm{C}_{\mathrm{a}}, \mathrm{C}_{\mathrm{b}}$ and $\mathrm{C}_{\mathrm{c}}$, are located across the load terminals. The proposed approach has its inherent capability in the applications where bi-directional power flow is important, such as motor drive.

Since only four ac switches are to be controlled, only four driving circuits for the corresponding ac switches are needed. Moreover, the proposed arrangement of the ac switches prevents the switches from conducting simultaneously as in bridge leg configuration. So, no dead time has to be considered in this topology. This will simplify the control design greatly. The ac switch can be constituted by one or two power transistors [13]. It can conduct bi-directional currents when turned on and block ac voltages when turned off. Figure 2 shows the methods to configure an ac switch. The first method is adopted in this paper since its conduction loss is less than the second one and its driving is easier. than the third one.

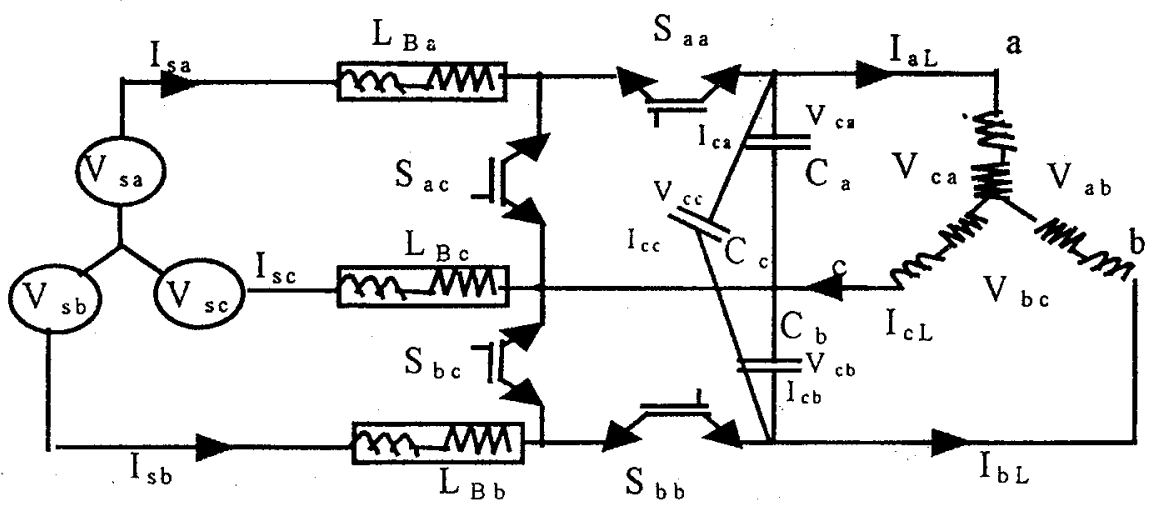

Fig 1 The proposed three-phase boost type voltage regulator 

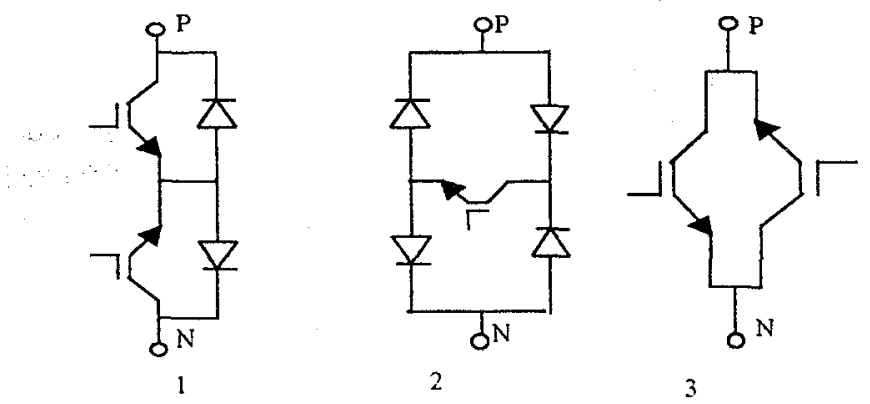

Fig. 2 Configuration of ac switches

\section{B. Modes of operation}

According to the proposed control strategy, there are only two modes of operation. These modes are described as follows;

Mode $1-S_{a c} S_{b c}$ ON and $S_{a a}, S_{b b}$ OFF : In this mode, the control circuit allows the supply currents to increase. At the same time, the stored energy in capacitors discharges into the load. When the supply currents $I_{s a, b, c}$ increase to be more than or equal to $\left(I_{s c a b, c}+H\right), S_{a c}$ and $\mathrm{S}_{\mathrm{bc}}$ are turned off. This mode is the boost mode.

Mode 2- $S_{a a}, S_{b b} O N$ and $S_{a c}, S_{b c} O F F$ : During this mode, the energy stored in the boost inductors is transferred to the capacitors giving rise to the capacitors voltage to increase. This mode continues until the supply currents $I_{s a, b, c}$ decrease less than or equal to $\left(\mathrm{I}_{\mathrm{sc} a \mathrm{~b}, \mathrm{c}}-\mathrm{H}\right)$, where $\mathrm{H}$ is the hysteresis band.

\section{The control Strategy}

In the proposed control scheme, three dependent hysteresis current controllers are used to obtain symmetrical supply currents and load voltages. Figure 3 shows the block diagram of the proposed control strategy. The voltage reference signal, $\mathrm{V}_{\text {ref }}$, is set according to the required load voltage. This signal can be treated as a dc value which is proportional with the load phase voltage. Using a peak value detector, the line voltage, $V_{c a}$, is converted to a corresponding dc value, $V_{d c}$. This value is compared with the reference voltage signal, $V_{\text {rer, }}$ and the error signal is passed through a proportional-integral controller (PI). The output of the controller, $\mathrm{V}_{0}$, is then multiplied by the unit vector of the supply phase voltages $\mathrm{V}_{\mathrm{sa}}, \mathrm{V}_{\mathrm{sb}}$ and $\mathrm{V}_{\mathrm{sc}}$ to produce the command currents $\mathrm{I}_{\mathrm{sca}}, \mathrm{I}_{\mathrm{scb}}$ and $I_{s c c}$, respectively. The supply currents $I_{s a}, I_{s b}$ and $I_{s c}$ are compared with their corresponding commands, $I_{s c a}, I_{s c b}$ and $I_{s c c}$ and the errors are processed through three dependent hysteresis controllers. The outputs of the hysteresis controllers are in the form of binary $\mathrm{HA}, \mathrm{HB}$ and $\mathrm{HC}$.

The inputs to the logic matrix are synchronized three phase supply voltages and the outputs are in the form of logic data, NA, NB and NC. The logic NA is ' 1 ' if the supply phase voltage, $V_{s a}$ is greater than $V_{s b}$ and $V_{s c}$. Otherwise it is ' 0 '. Similarly, the logic NB is ' 1 ' if $V_{s b}$ is greater than $V_{s a}$ and $V_{s c}$. Otherwise it is ' 0 '. Also, the logic $N C$ is ' $l$ ' if $V_{s c}$ is greater than $V_{s a}$ and $V_{s b}$. Otherwise it is ' 0 '. The outputs of the hysteresis comparators, $\mathrm{HA}, \mathrm{HB}, \mathrm{HC}$, and the outputs of the logic matrix, NA, NB, NC are fed to the logic switches. The logics $\mathrm{HA}, \mathrm{HB}$ and $\mathrm{HC}$ pass to the output through the logic switches if the logics NA, NB and NC are ones. Otherwise they are blocked. The output of the logic switches are in the form of binary signals, $\mathrm{NS}_{\mathrm{aa}}, \mathrm{NS}_{\mathrm{bb}}, \mathrm{NS}_{\mathrm{ac}}$ and $\mathrm{NS}_{\mathrm{bc}}$. The logic $\mathrm{NS}_{\mathrm{aa}}$ is the same as logic $N S_{b b}$, and the logic $N S_{a c}$ is the same as logic $N S_{b c}$. If the input current is 
greater than the current command, the digital signal is ' 0 '. Otherwise it is ' $\mathrm{I}$ '. Note that the logics $\mathrm{NS}_{\mathrm{ac}}$ and $\mathrm{NS}$ bc are complementary of logics $N \mathrm{~S}_{\mathrm{aa}}$ and $\mathrm{NS}$ bb. Those logic signals will be used to fire the four ac switches.

If the supply current is controlled to follow the current command, it follows the supply voltage in its waveform and follows the reference voltage in its magnitude. This actually is achieved, since the reference current is generated from and synchronized with the supply voltage. This control strategy ensures that the input power factor is almost kept at unity.

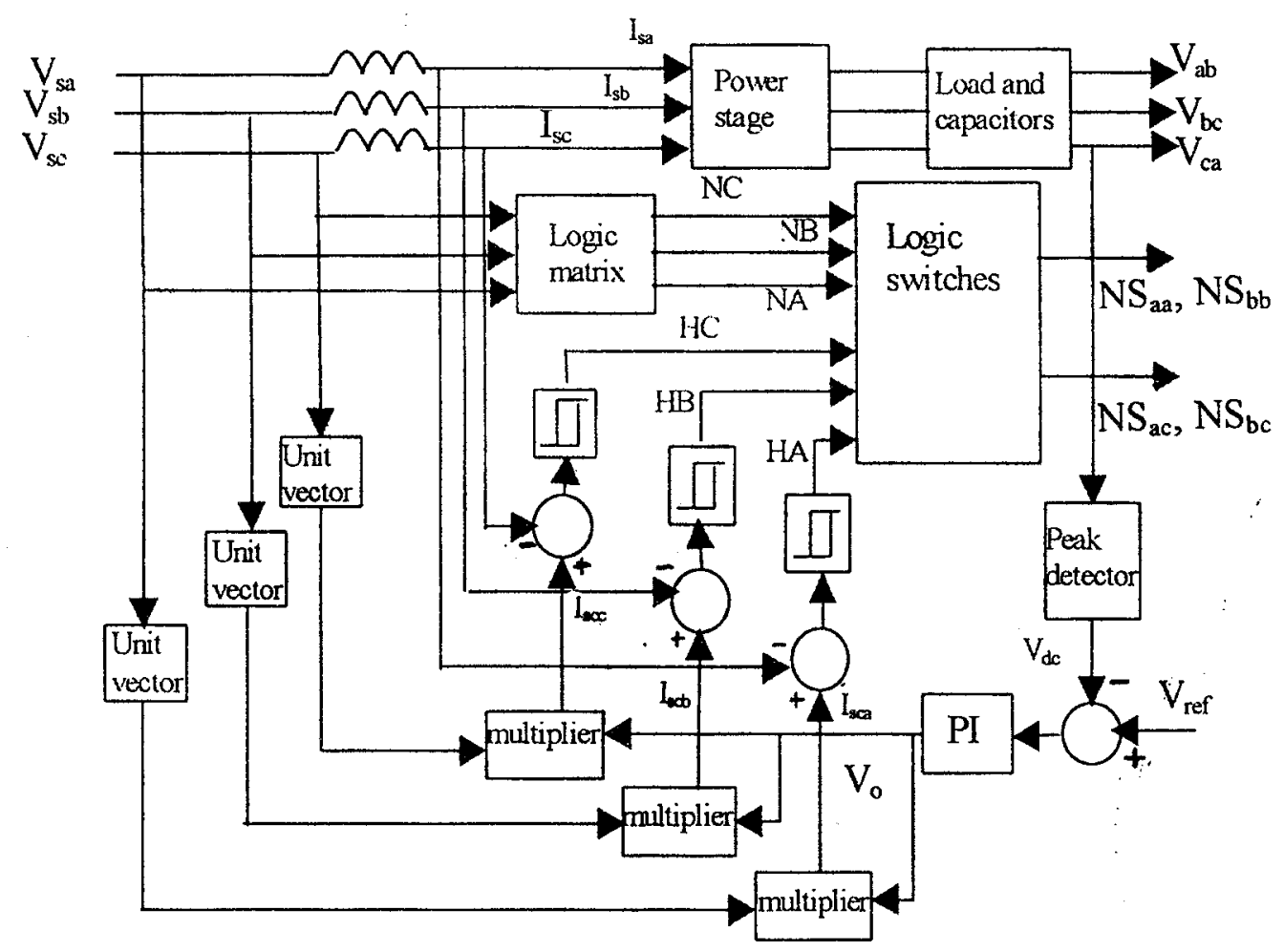

Fig. 3 Block diagram of the proposed control strategy

\section{Modeling and Analysis}

The equations covering Mode $l$ are given as:

$$
\begin{aligned}
& \frac{d I_{s a}}{d t}=\frac{V_{s a}-V_{s c}}{L_{B a}+L_{B c}}-\frac{R_{B a}+R_{B c}}{L_{B a}+L_{B c}} I_{s a} \\
& \frac{d I_{s b}}{d t}=\frac{V_{s b}-V_{s c}}{L_{B b}+L_{B c}}-\frac{R_{B b}+R_{B c}}{L_{B b}+L_{B c}} I_{s b} \\
& \frac{d^{2} I_{a L}}{d t^{2}}+\frac{R_{a L}}{L_{a L}} \frac{d I_{a L}}{d t}-\frac{1}{L_{a L} C a} I_{c a}=0 \\
& \frac{d^{2} I_{b L}}{d t^{2}}+\frac{R_{b L}}{L_{b L}} \frac{d I_{b L}}{d t}-\frac{1}{L_{b L} C b} I_{c b}=0
\end{aligned}
$$


$\frac{d^{2} I_{c L}}{d t^{2}}+\frac{R_{c L}}{L_{c L}} \frac{d I_{c L}}{d t}-\frac{1}{L_{c L} C c} I_{c c}=0$

where

$\left[\begin{array}{lll}I_{c a} & I_{c b} & I_{c c}\end{array}\right]^{T}=-\left[\begin{array}{lll}I_{a L} & I_{b L} & I_{c L}\end{array}\right]^{T}$

The equations covering Mode 2 are given as:

$$
\begin{aligned}
& \frac{d I_{s a}}{d t}=\frac{V_{s a}}{L_{B a}}-\frac{R_{B a}}{L_{B a}} I_{s a}-V_{c a}^{r} \\
& \frac{d I_{s b}}{d t}=\frac{V_{s b}}{L_{B b}}-\frac{R_{B b}}{L_{B b}} I_{s b}-V_{c b}^{r} \\
& \frac{d I_{s c}}{d t}=\frac{V_{s c}}{L_{B c}}-\frac{R_{B c}}{L_{B c}} I_{s c}-V_{c c}^{r} \\
& \frac{d I_{a b .}}{d t}=\frac{V_{c a}}{L_{a L}}-\frac{R_{a L} I_{a L}}{L_{a L}} \\
& \frac{d I_{b L}}{d t}=\frac{V_{c b}}{L_{b L}}-\frac{R_{b L} I_{b L}}{L_{b L}} \\
& \frac{d I_{c L}}{d t}=\frac{V_{c c}}{L_{c L}}-\frac{R_{c L} I_{c L}}{L_{c L}}
\end{aligned}
$$

where ,

$$
\begin{aligned}
& I_{c a}=I_{s a}-I_{a L}-I_{c c} \\
& I_{c b}=I_{s b}-I_{b L}-I_{c c} \\
& I_{c c}=I_{c b}+I_{c a}
\end{aligned}
$$

and,

$$
\begin{aligned}
& V_{c a}=\frac{1}{C a} \int I_{c a} d t \\
& V_{c b}=\frac{1}{C b} \int I_{c b} d t \\
& V_{c c}=\frac{1}{C c} \int I_{c c} d t
\end{aligned}
$$


$D F_{s}=\sqrt{\left(\sum_{n=2}^{\infty} I_{s n}^{2}\right) / I_{s 1}^{2}}$

where $I_{s 1}$ is the rms value of the fundamental component of the supply current. The input power factor is given by:

$P F_{s}=\cos \phi_{1} / \sqrt{1+\left(D F_{s}\right)^{2}}$

where $\phi_{1}$ is the angle between the fundamental component of the supply current $I_{s 1}$ and the phase supply voltage $\mathrm{V}_{\mathrm{sa}}$ (or $\mathrm{V}_{\mathrm{sb}}$ or $\mathrm{V}_{\mathrm{sc}}$ ).

The load distortion factor $\mathrm{DF}_{\mathrm{L}}$ is defined as:

$D F_{L}=\sqrt{\left(\sum_{n=2}^{\infty} V_{L n}^{2}\right) / V_{L 1}^{2}}$

where $V_{L n}$ is the rms value of $n$-th harmonic component of the load voltage. On the other hand, $V_{L, 1}$ is the rms value of the fundamental component of the load voltage.

\section{DSP-based control}

The control scheme of Fig. 3 is implemented in real time using a 32-bit digital signal processor (DSP)(TMS320C31), as shown in Fig. 4. The ac switches are constructed using insulated gate bipolar transistors (IGBT's). The voltage isolators sense the unit vectors of supply voltages. These sensed signals are used for synchronization of the generated reference currents. The supply currents, $I_{s a}, I_{s b}$ and $I_{s c}$ are measured by using Halleffect devices. The voltage and current signals are then fed to the DSP through 12-bit ADD converters. The output from the DSP(digital $1 / 0$ ) are in the form of logic pulses, $\mathrm{NS}_{\mathrm{aa}}, \mathrm{NS}_{\mathrm{ac}}, \mathrm{NS}_{\mathrm{bb}}$ and $\mathrm{NS}_{\mathrm{bc}}$. These logic signals are then fed to the ac switches through isolation and driving stage. The overall execution time of the control scheme is $50 \mu \mathrm{sec}$ at sampling frequency of $20 \mathrm{kHz}$.

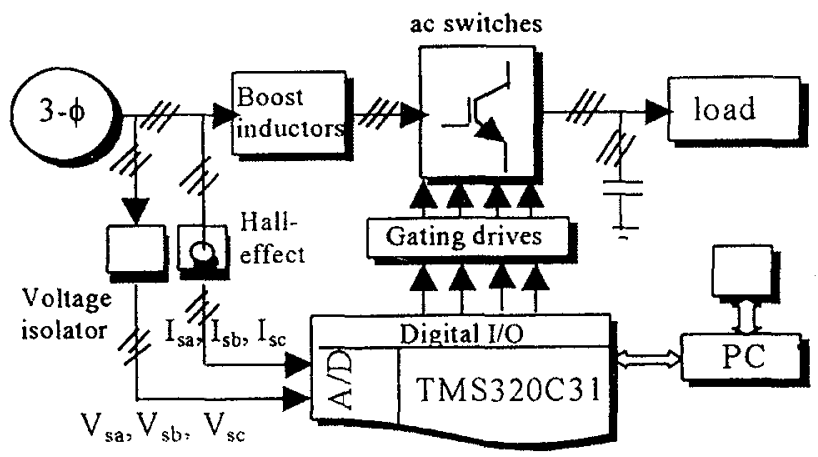

Fig. 4 Hardware implementation

\section{Results}

An experimental three-phase boost-type voltage regulator with the proposed control strategy has been built and tested. Simulation and experiment are carried out to explore the characteristics of the proposed boost regulator. The circuit parameters of the proto- 
type are listed in the appendix. The supply voltage is kept constant at $150 \mathrm{~V}$ line to line and the reference voltage is controlled to allow boosting of the output voltage.

Figure 5 shows the simulation results of the threc-phase regulator for the boosting of approximately $200 \%$ of the input voltage. Figure 5 (a) shows the supply phase voltage $\left(V_{s a}\right)$ and the supply phase current $\left(I_{\mathrm{sa}}\right)$. It is clear from Fig.5(a) that the supply current follows the supply voltage in its waveshape with almost a unity displacement power factor. Using the proposed control strategy ensures balanced three-phase currents, as shown in Fig.5(b). Figure (c) shows the spectrum of the supply current. Also, the proposed control strategy ensures symmetrical load voltages as shown in Fig. 5(d). The spectrum of these load voltages is shown in Fig. 5(e). It is erident form Figs. $5(\mathrm{~d})$ and (e) that the load voltage is almost $200 \%$ of the input voltage. The line load voltage and current are shown in Fig. 5(f). The experimental results in Fig. 6 confirm, very closely, the corresponding simulated results of Fig. 5. Figure 7 shows the power factor, distortion factor of the load voltage and distortion factor of the supply current over a wide range of load voltage. Figure 8 shows the rms of the load voltage due to step change of the reference voltage, $V_{\text {ref, }}$. The fast response ensures the effectiveness and robustness of the proposed control strategy: The results show the effectiveness and efficacy of the proposed controller for boosting operation.
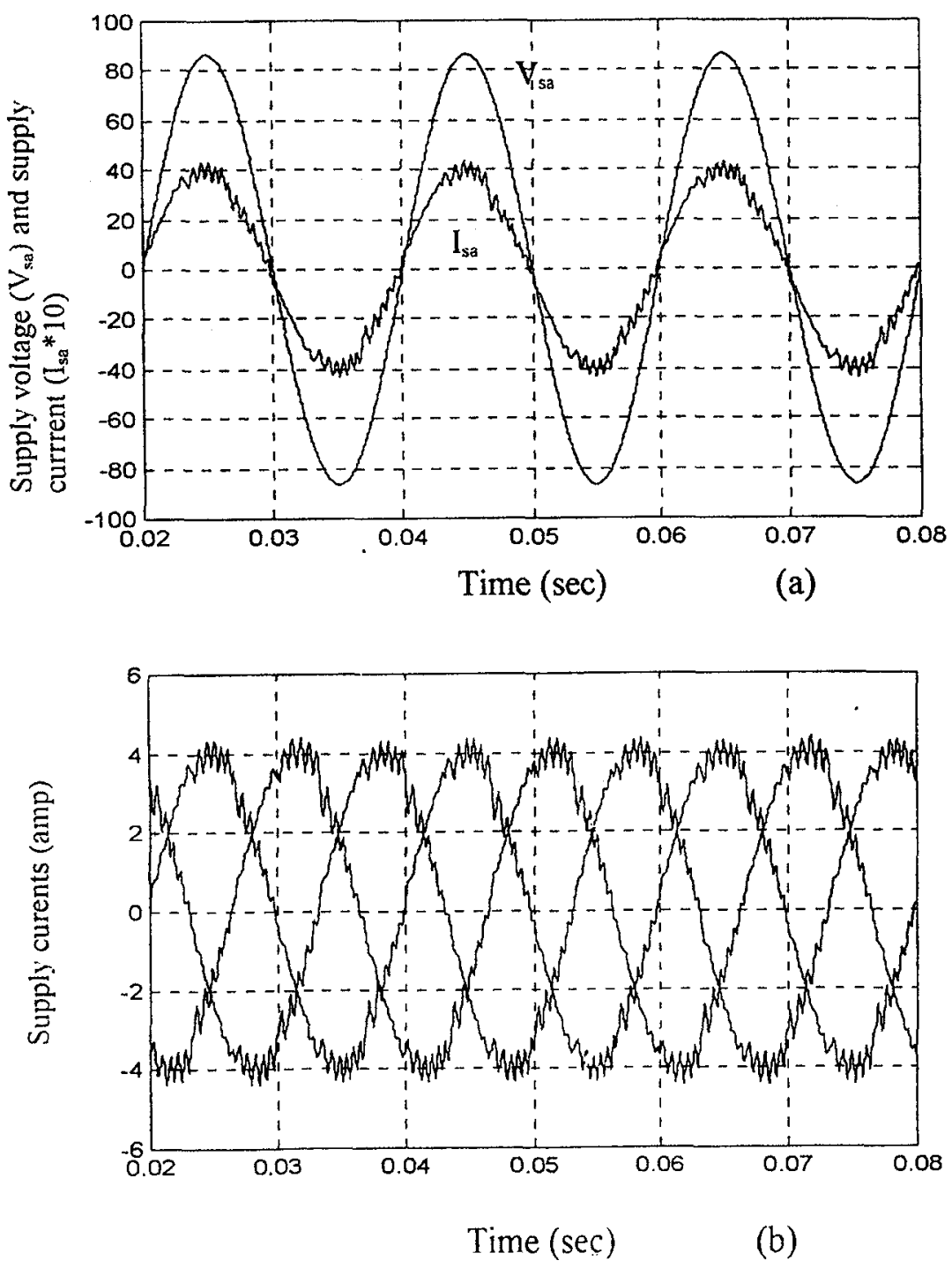


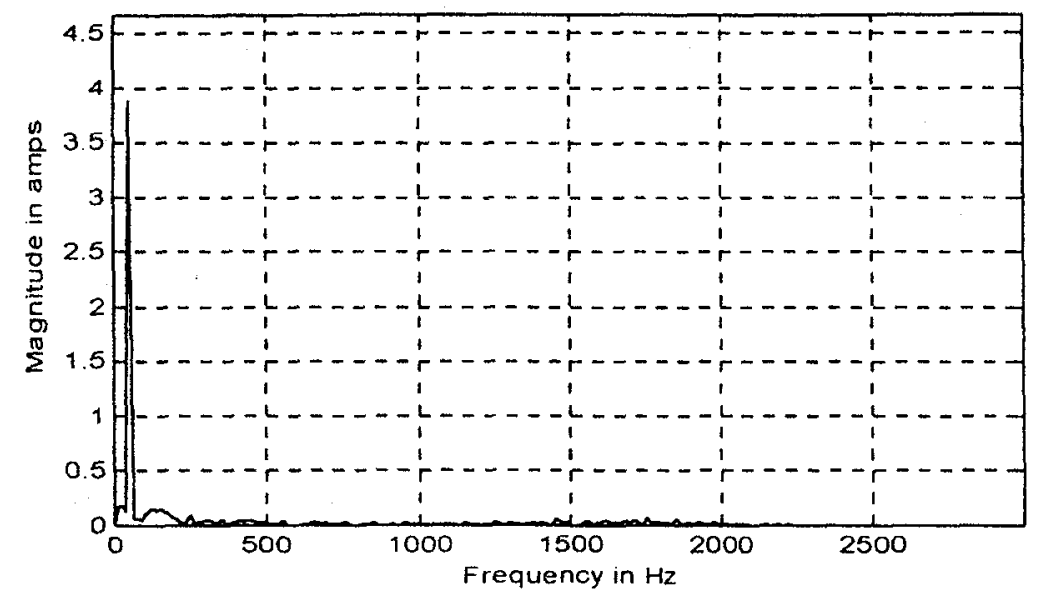

Time (sec)

(c)
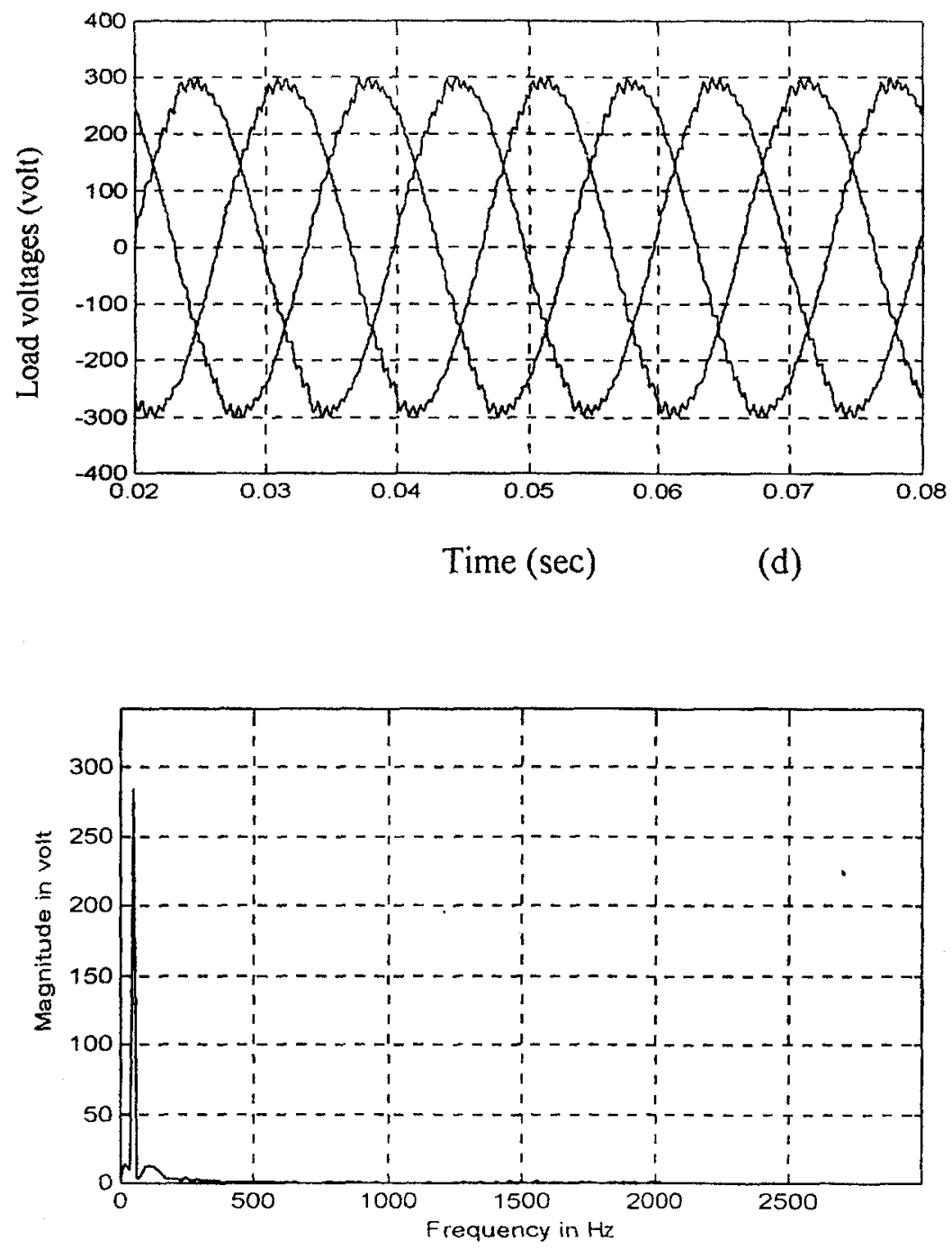

Time (sec)

(e) 


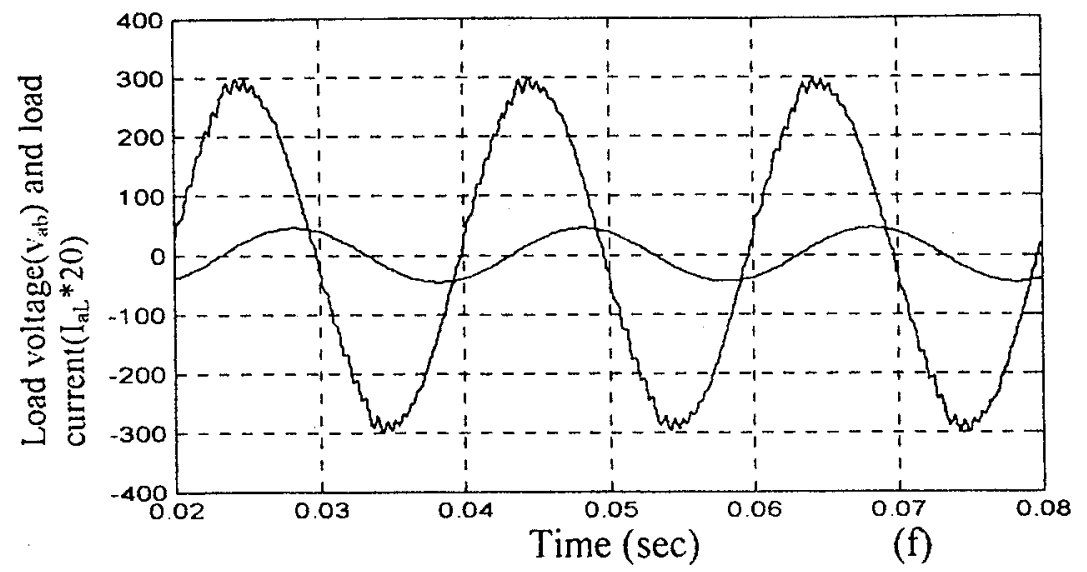

Fig.5 Simulation results of the boost regulator; (a) supply voltage and current: (b) supply currents; (c) spectrum of supply current; (d) load voltages; (e) spectrum of load voltage; and $(f)$ load voltage and current.

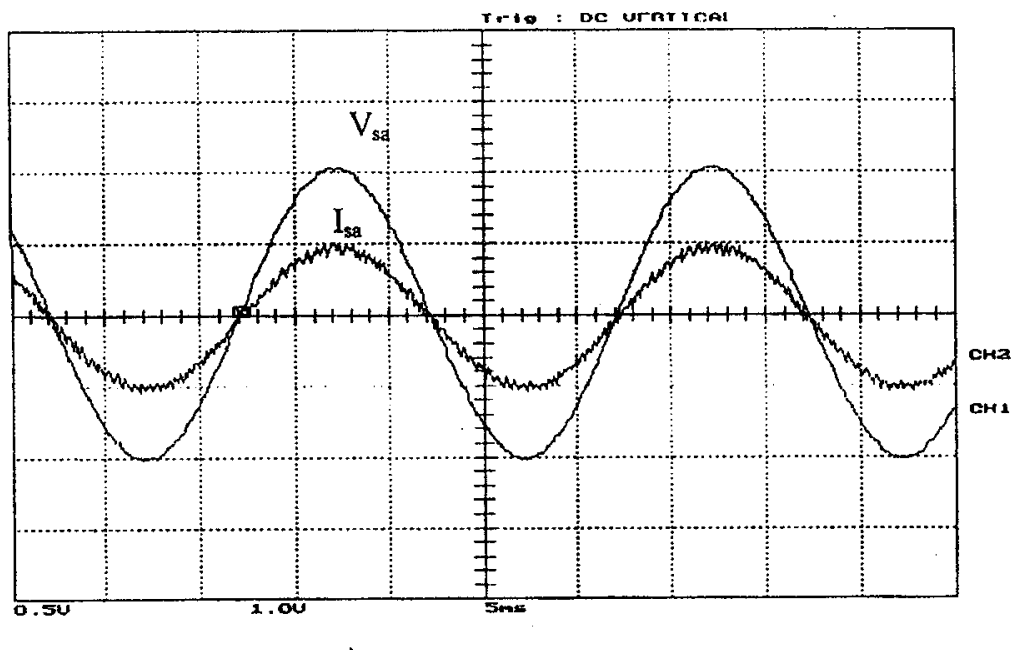

(a)

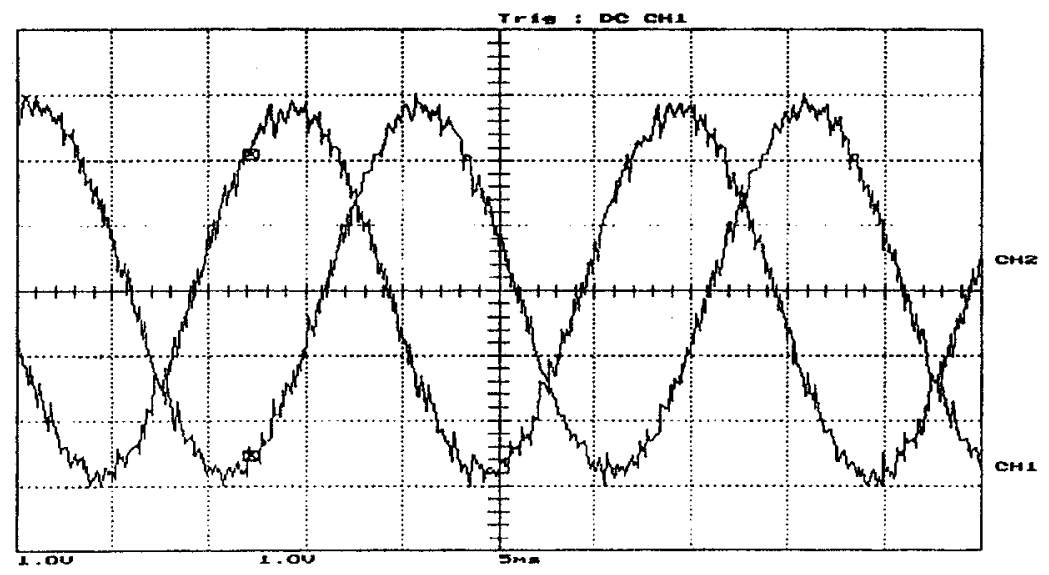

(b) 


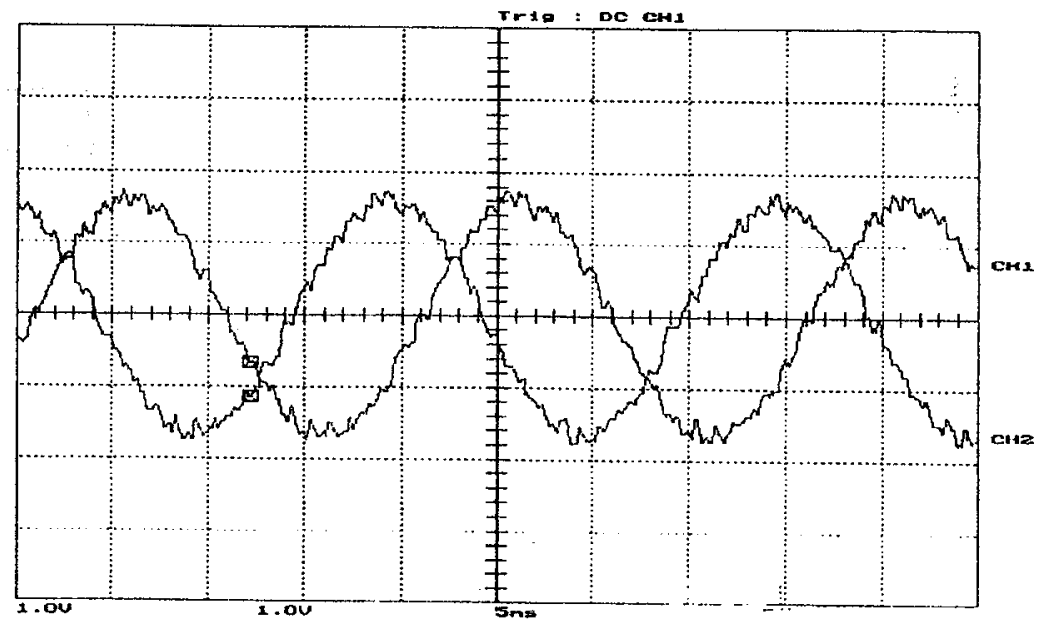

(c)

Fig. 6 Experimental results of the boost regulator; (a) supply voltage and current, $\mathrm{V}_{\mathrm{sa}}=43 \mathrm{~V} / \mathrm{div}, \mathrm{I}_{\mathrm{sa}}=4 \mathrm{~A} / \mathrm{div}$; (b) supply currents, $1.4 \mathrm{~A} / \mathrm{div}$; and (c) load voltages, $180 \mathrm{~V} / \mathrm{div}$.

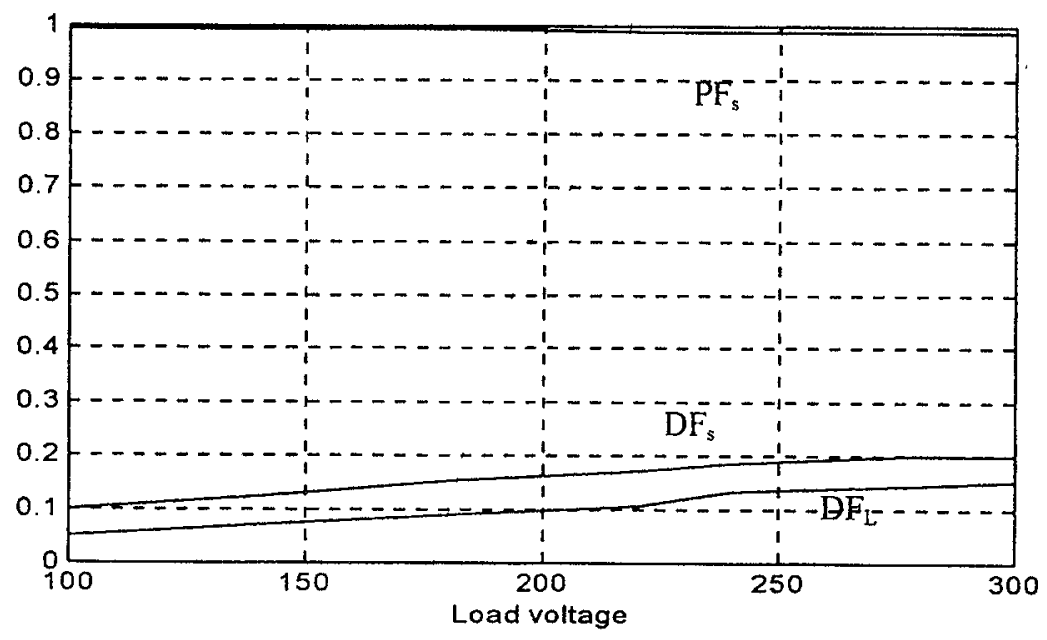

Fig. 7 Supply power factor, PF; supply current distortion factor, $\mathrm{DF}_{\mathrm{s}}$; and load voltage distortion factor, $\mathrm{DF}_{\mathrm{L}}$, versus load voltage. 


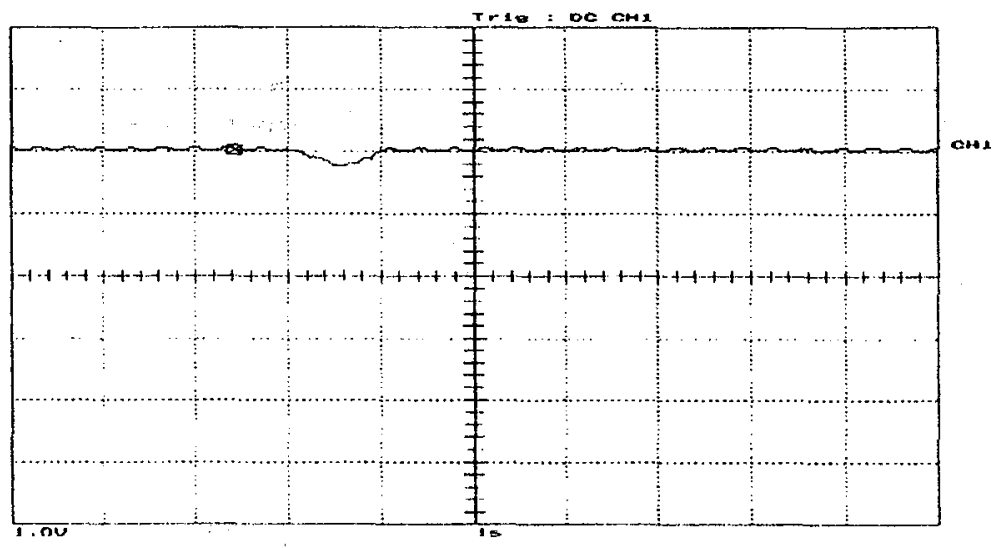

Fig. 8 RMS of the load voltage due to step change of the reference voltage

\section{Conclusions}

A new control strategy for high performance three-phase boost-type voltage regulator with nearly unity input power factor has been proposed. The control scheme using three dependent hysteresis current controller has been implemented. The operation and modeling of the boost regulator have been described and analyzed. Since the regulator employed only four ac switches, the presented approach make the operational principle clear and gives the possibility of simple control design and implementation. The regulator is effectively an electronic step-up coreless transformer. It has the ability to step up the voltage to more that $200 \%$. An experimental regulator based on DSP-controlled has been built to explore the advantages and the practical limitations of the three-phase boost-type voltage regulator with the proposed control strategy.

\section{Appendix I}

Data and parameters of the circuit topology.

$\mathrm{V}_{\mathrm{sa}}=\mathrm{V}_{\mathrm{sb}}=\mathrm{V}_{\mathrm{sc}}=150 \sqrt{3} \mathrm{~V}, \quad \mathrm{~L}_{\mathrm{Ba}}=\mathrm{L}_{\mathrm{Bb}}=\mathrm{L}_{\mathrm{Bc}}=30 \mathrm{mH}$

$\mathrm{R}_{\mathrm{Ba}}=\mathrm{R}_{\mathrm{Bb}}=\mathrm{R}_{\mathrm{Bc}}=1.4 \Omega, \quad \mathrm{C}_{\mathrm{a}}=\mathrm{C}_{\mathrm{b}}=\mathrm{C}_{\mathrm{c}}=15 \mu \mathrm{F}$

Load side; three phase balanced $R-L$ with $R_{L}=60 \Omega$ and $L_{L}=130 \mathrm{mH}$

\section{References}

[1] E.C. Servetas and A.V. Valachakis, "A New ac Voltage Regulator Using Thyristors" , IEEE Transactions on Industrial Electronics and Control Instrumentation, vol. IECI-28, no.2, May, 1981. pp.140-145.

[2] M. Kang, P.N. Enjeti and I.J Pitel, "Analysis and Design of Electronic Transformers for Electric Power Distribution System", IEEE/IAS Annual Meeting, New Orleans, Lousiana. October, 1997, pp. 1689-1694

[3] Yim-Shu Lee, David K.W. Cheng and Y. C. Cheng. " Design of a Novel ac Regulator", IEEE Transactions on Industrial Electronics, vol. 38, no. 2, 1991, pp.89-94 
[4] J.C. Bowers, S.J. Garrett, H.A. Nienhaus and J.L. Brooks, "A solid State Transformer", IEEE /PESC Conference Record, 1980, pp253-264.

[5] K.H. Liu, R. Orugati and F.C. Lee, "Quasi-Resonant Converter-Topologies and Characteristics", IEEE Transactions on Power Electronics, vol. PE-2, no.1, January 1987, pp.62-71.

[6] C.E. Thomas, "Electronic Power Conditioner", IEEE Applied Power Electronics, Conference Proceedinds, 1986, pp.46-51.

[7] J. Arrillaga and R. M. Duke, "A static Alternative to the Transformer on-Load Tap Changer", IEEE Transactions on Power Apparatus and System, PAS-099, no. I, 1980 , pp.86-91

[8] A.E. Lashine, " A Thyristorized Saturable Reactor With Self Excitation", Electric machines and Power Systems, USA, vol.24, no.4, 1996, pp.437-449

[9] D. M. Divan, "Inverter Topologies and Control Techniques for Sinusoidal Output Power Supplies", IEEE/ APEC Conference Record, vol.1, 1991, pp.81-87

[10] K. M. Rahman, M.A. Choudhary and M.A. Rahman, "Hysteresis Current Controlled PWM Buck Converter for AC/AC Voltage Control". Proceedings of the International Power Engineering Conference, vol. II, Singapore, 22-24, May 1997, pp.703-706

[11] R. Strzelecki and Z. Fedyczak, "Properties and Structures of Three-Phase PWM AC Power Controllers", IEEE-PESC'96, 1996, pp.740-746

[12] T.S. Radwan, A.E. Lashine and M.A. Rahman, " A New Three-Phase Boost-Type Voltage Regulator With Unity Input Power Factor", International Conference of Power Electronics, IPEC-Tokyo, April 3-7 2000.

[13] T.S. Radwan, A.E. Lashine and M.A. Rahman, "A Novel AC/AC Buck-Boost Voltage Regulator With Unity Input Power Factor", International Journal of Electronics, vol. 87 , no. 2, February 2000. 


$$
\begin{aligned}
& \text { داتوفيت سعد رضوان } \\
& \text { قسم الهندسة الكهر بية } \\
& \text { كلية الهندسة-جامعة المنوفية }
\end{aligned}
$$

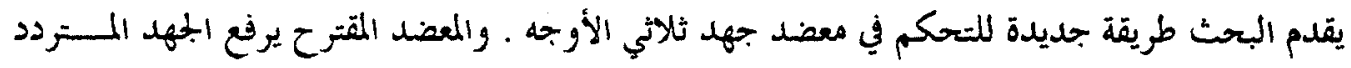

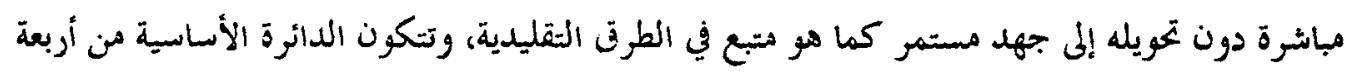

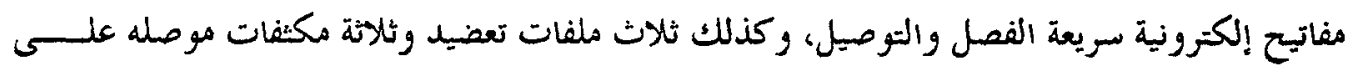
شكل دلتا. بحيث توصل هذه المكونات بين الحمل ومنبع الجهل المتردد الثابت.

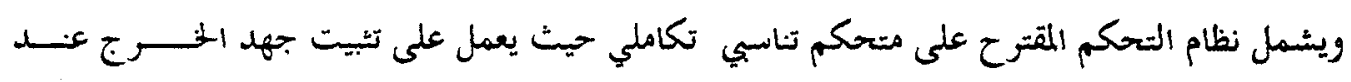

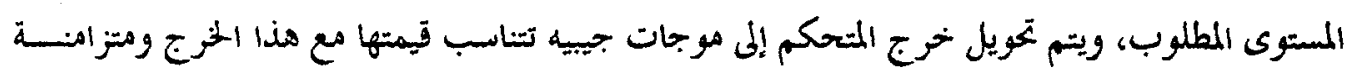

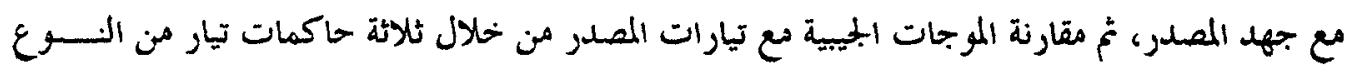

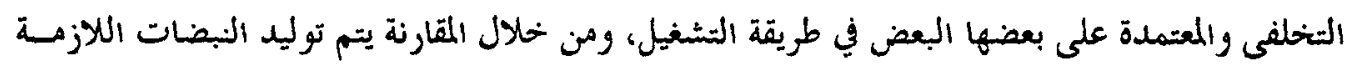

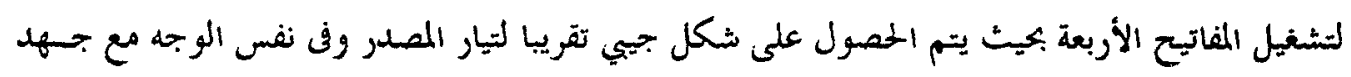

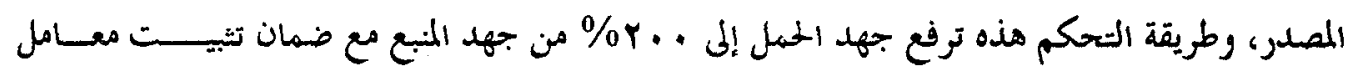

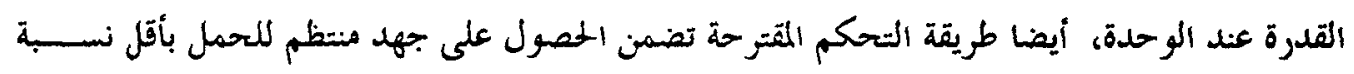

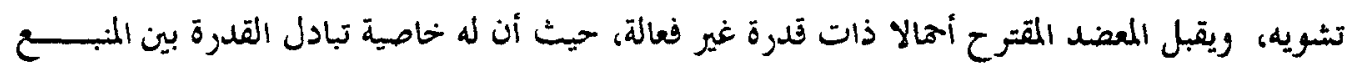

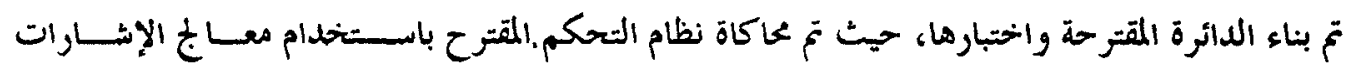

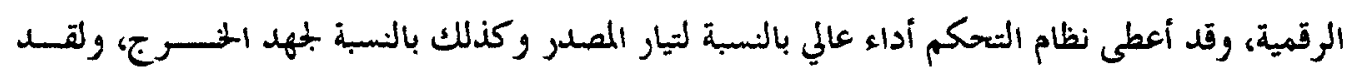
أوضحت النتائج النظرية و العملية أن تيار المصدر جيبي تقريبا وفى نفس الوجه مع الجههد، مما يجعل معـلهل

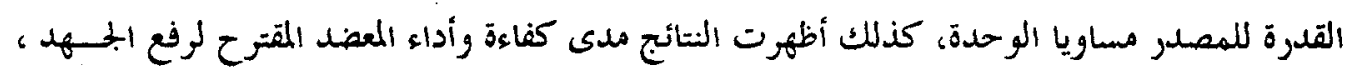
مما يشجع على استخدامه كمحول إلكتروبي بديل عن الغول التقليدي للقدرات المنخفضة والمتوسطة. 